\title{
Phytosynthesis of zinc oxide nanoparticles using methanol extract of Senna alata leaf: Characterization, optimization, antimicrobial properties, and its application in cold cream formulation
}

\author{
Bukola Christianah Adebayo-Tayo ${ }^{1, A, D-F}$, Samuel 0. Borode ${ }^{1, B-D, F}$, Olusola Ademola Olaniyii ${ }^{2, A, E, F}$ \\ ${ }^{1}$ Department of Microbiology, University of Ibadan, Nigeria \\ 2 Department of Mathematics and Computer Science, University of North Carolina, Pembroke, USA \\ A - research concept and design; $\mathrm{B}$ - collection and/or assembly of data; $\mathrm{C}$ - data analysis and interpretation; \\ $D$ - writing the article; $E$ - critical revision of the article; $F$ - final approval of the article
}

Address for correspondence

Bukola Christianah Adebayo-Tayo

E-mail: emailbukola.tayo@gmail.com

Funding sources

None declared

Conflict of interest

None declared

Received on November 22, 2019

Reviewed on May 9, 2020

Accepted on May 27, 2020

Cite as

Adebayo-Tayo B, Borode S, Olaniyi 0. Phytosynthesis of zinc oxide nanoparticles using methanol extract of Senna alata leaf: Characterization, optimization, antimicrobial properties, and its application in cold cream formulation. Polim Med. 2020;50(1):5-19. doi:10.17219/pim/122901

DOI

10.17219/pim/122901

Copyright

○ 2020 by Wroclaw Medical University

This is an article distributed under the terms of the

Creative Commons Attribution 3.0 Unported (CC BY 3.0)

(https://creativecommons.org/licenses/by/3.0/)

\begin{abstract}
Background. Phyto-reduction using Senna alata methanol leaf extract for nanoparticle (NP) biosynthesis is of great importance for the production of value-added nanomaterial with antimicrobial potential.

Objectives. The aim of this study was to investigate the biosynthesis of zinc oxide nanoparticles (ZnONPs) using crude methanol leaf extract of S. alata (SaZnONPS), antimicrobial efficacy of this extract, optimization of its production parameters, and its application in cold cream formulation.
\end{abstract}

Material and methods. Phytosynthesized SaZnONPs were characterized using UV-Vis absorption spectroscopy, Fourier-transform infrared spectroscopy (FTIR), scanning electron microscopy (SEM), thermogravimetric analysis (TGA), dynamic light scattering (DLS), X-ray diffraction (XRD) analysis, and energy-dispersive X-ray (EDX) spectroscopy. The antimicrobial activity of SaZnONPs and the formulated cold cream was evaluated.

Results. The SaZnONPs surface plasmon resonance (SPR) was $400 \mathrm{~nm}$. Functional groups such as alkenes, alkynes and alkyl aryl ether were present. The SEM image showed NPs $7.10 \mathrm{~nm}$ in size and with a needle-like shape. The TGA values show the formations of stable ZnONPs, while the DLS showed the particle diameter average of $89.7 \mathrm{~nm}$ and $855.4 \mathrm{~nm}$ with 0.595 polydispersity index. The EDX analysis confirmed the formation of pure ZnONPS, and the crystallinity was confirmed with XRD analysis. Twenty-four hours of incubation and production at pH13 was optimal for NPs synthesis. The SaZnONPs and the formulated cold cream have antimicrobial properties against some pathogenic bacteria and Pichia sp. (16.00 mm) and Trichophyton interdigitale $(11.00 \mathrm{~mm})$.

Conclusions. Senna alata was able to serve as a stabilizing and capping agent for SaZnONPs biosynthesis. The SaZnONPs had good antimicrobial potential and can be used in cold cream formulation.

Key words: antibacterial, zinc oxide nanoparticles, Senna alata, cold cream formulation, Pichia species 


\section{Introduction}

The problem of drug resistance has been a serious challenge to the wellbeing of the world population, which necessitates the search for new drugs with high antimicrobial potency to combat the existing resistant microorganisms. Nanotechnology has proven to be one of the most valuable means of synthesizing antimicrobial agents with a broad spectrum of activity. Noble metals such as silver, gold, zinc, copper, and iron are bio-converted by microbial and plant metabolites for nanoparticle (NP) synthesis; the NPs are widely used in drug delivery systems. Nanoparticle synthesis is an important field in nanotechnology as a result of material properties based on size. ${ }^{1}$

Zinc oxide nanoparticles ( $\mathrm{ZnONPs}$ ) have received considerable attention due to their unique antibacterial, antifungal and UV filtering properties, and high catalytic and photochemical activities, which are not observed at bulk phase. ${ }^{2-4}$ Specifically, ZnONPs have a tremendous potential in biological applications like biological sensing, biological labelling, gene delivery, drug delivery, and nano-medicines due to their antibacterial, antifungal, anti-diabetic, anti-inflammatory, wound-healing, antioxidant, and optical properties. ${ }^{5,6}$

Zinc oxide nanoparticles can be synthesized using direct precipitation, homogeneous precipitation, solvothermal, sonochemical, reverse micelles, sol-gel, hydrothermal, thermal decomposition, and microwave irradiation methods. ${ }^{7}$ Applerot et al. reported that ZnONPs exhibited stronger inhibitory activity against pathogenic microorganisms than chemically synthesized NPs. ${ }^{8}$ The antibacterial potential of ZnONPs against some clinical pathogens has been reported. ${ }^{9}$

Green method of ZnONPs biosynthesis is gaining importance due to its simplicity, eco-friendliness, broad antimicrobial efficiency, and environmental control of chemical toxicity. ${ }^{10,11}$ There is an increasing interest in the biosynthesis of metal NPs using plants as bio-reducing and capping agents based on their suitability for large scale production of NPs. Nanoparticles produced using plants are characterized by better stability and diversity in shape and size compared to the NPs produced using other organisms. ${ }^{12}$

Among the wide range of medicinal plants are members of the genus Senna. Senna alata is an ornamental shrub which is mostly used as antimicrobial agent. ${ }^{13,14}$ The plant has been used for treating a wide variety of infections and diseases. ${ }^{15,16}$ Senna alata has been reported to contain phytochemicals which are responsible for their biological actions against various pathogens. This has made it an important plant in various fields of relevance. ${ }^{14,16}$

Biosynthesis of ZnONPs using different plants such as Aloe vera extract, Citrus aurantifolia extract, Plectranthus amboinicus, orange juice, Ocimum basilicum L. var. urpurascens, and Parthenium hysterophorus L. has been reported. ${ }^{17-21}$

The antibacterial efficacy of the biosynthesized ZnONPs using ethanol extract of Murraya koenigii against some bacteria has been reported. ${ }^{22}$ This research aimed at examining the phytosynthesis of ZnONPs using crude methanol leaf extract of $S$. alata, as well as at optimization of production parameters, antimicrobial efficacy and application of the $\mathrm{ZnONPs}$ in cold cream formulation.

\section{Material and methods}

\section{Plant collection and extraction}

Fresh leaves of S. alata were collected from the premises of the University of Ibadan, Nigeria. The leaves were cleaned with running tap water and rinsed with distilled water to remove debris and contaminants. The leaves were air-dried at room temperature, chopped into small pieces, milled, poured into a macerating jar, and methanol was added and filled to the brim. The solvent was then stirred with the solute using a sterilized glass rod and this was repeated every $8 \mathrm{~h}$ during a cycle which lasted for $72 \mathrm{~h}$. After $72 \mathrm{~h}$ of extraction, the extract was decanted and filtered using a Whatman's filter paper (No. 1), and then concentrated using a rotary evaporator under reduced pressure and low temperature.

\section{Collection of test cultures}

Typed strains (Pseudomonas aerogenosa (ATCC 27853), Staphylococcus aureus (ATCC 29213), Bacillus sp., Escherichia coli (ATCC 11775), and E. coli (ATCC 35218)) and clinical strains (5 strains of Multi Drug Resistant Staphylococci (MRS) and fungi (Candida albicans, Candida krusei, Candida tropicalis, Trichophyton sp., Aspergillus niger, and Penicillium sp.)) were obtained from the Department of Microbiology of the University of Ibadan.

\section{Photosynthesis of zinc oxide nanoparticles}

The ZnONPs was biosynthesized using methanol leaf extract of $S$. alata. The plant extract was added to $10 \mathrm{mM}$ zinc acetate solution in ratio of 1:50. The mixture was incubated for $24 \mathrm{~h}$ to facilitate the formation of NPs. Aqueous leaf extract and zinc acetate solution were used as controls throughout the experiments. Change in the color of the solution indicated the presence of ZnONPs. The NPs were dried at $60^{\circ} \mathrm{C}$ to obtain a pale white powder.

\section{Characterization of nanoparticles}

\section{Visual observation and UV-Vis spectra analysis}

The gradual color change of the mixture in the test bottle was visually observed and noted. The formation and stability of the NPs was monitored by measuring the absorbance using UV-Vis spectrophotometry (UV-Vis spectrophotometer; Ocean Optics, Winter Park, USA). The optical property 
of the NPs was determined using ultraviolet and visible absorption spectroscopy in the range of $200-800 \mathrm{~nm}$ at a resolution of $1 \mathrm{~nm}$. The UV-Vis spectra were recorded at 24-72 $\mathrm{h}$.

\section{Fourier-transform infrared spectroscopy analysis}

The functional group and composition of the $\mathrm{ZnOPS}$ synthesized using crude methanol leaf extract of $S$. alata (SaZnONPs) was determined using Fourier-transform infrared spectroscopy (FTIR) spectroscopy (Shimadzu, Kyoto, Japan). Two milligrams of the SaZnONPs was ground with $\mathrm{KBr}$ salt at $25^{\circ} \mathrm{C}$ and pressed into a mold to form a pellet. The spectra were recorded at a wave range of $500-4000 \mathrm{~cm}^{-1}$ and at a resolution of $4 \mathrm{~cm}^{-1}$.

\section{Scanning electron microscopy analysis}

The size and shape of the SaZnONPs were determined using scanning electron microscopy (SEM). Thin films of dried SaZnONPs were gold-coated using a coater (Model No. JFC-1600; JEOL, Akishima, Japan). The images of SaZnONPs were obtained in a SEM (Zeiss EVOMA 10; Carl Zeiss AG, Oberkochen, Germany). Details regarding applied voltage, magnification and size of the contents of the images were also implanted on the images.

\section{Thermogravimetric analysis}

Thermogravimetric analysis (TGA) was done on the dried SaZnONPs in SDT 2960 device (TA Instruments, New Castle, USA). The samples were heated in open alumina pans from $40^{\circ} \mathrm{C}$ to $600^{\circ} \mathrm{C}$, under an oxidant atmosphere $\left(\mathrm{O}_{2}\right)$, flux of $50 \mathrm{~mL} / \mathrm{min}$ and a heating rate of $10^{\circ} \mathrm{C} / \mathrm{min}$. The estimation of the zinc content in SaZnONPs was done using the residue at $600^{\circ} \mathrm{C}$.

\section{Dynamic light scattering}

Particle size distribution and average size of SaZnONPs was determined using PSI Online Diameter-Measuring Particle Size Analyzer (DFMC, Dandong, China). Liquid sample before centrifugation was diluted 10 times using deionized water and transferred to cuvette, and analysis was performed using dynamic light scattering (DLS) (Malvern Zetasizer Nano Z500; Malvern Panalytical, Malvern, UK). The sample holder temperature was maintained at $25^{\circ} \mathrm{C}$.

\section{Energy-dispersive X-ray spectroscopy}

The elemental analysis of SaZnONPs was determined using an energy-dispersive X-ray (EDX) spectroscopy. The dried SaZnONPs powder was used for the analysis and pure $\mathrm{ZnO}$ was used as standard. The EDX analysis software from Oxford Instruments (Abingdon, UK) was used. All measurements were performed at an accelerated voltage of $10 \mathrm{kV}$.

\section{X-ray diffraction analysis of SaZnNPs}

The purity and crystalline structure of the SaZnONPs was determined using X-ray diffraction (XRD) analysis. X-ray diffraction patterns were obtained in a Siemens Kristalloflex diffractometer (Siemens AG, Munich, Germany) using nickelfiltered $\mathrm{Cu}-\mathrm{K} \alpha$ radiation from $4^{\circ}$ to $70^{\circ}$ (2 $\theta$ angle).

\section{Determination of antimicrobial potential of the SaZnONPs}

The antibacterial and antifungal potential of the SaZnONPs was determined using agar well diffusion method. ${ }^{23}$ The isolates were cultured overnight in peptone water and 18 hour-old culture of the isolate was seeded on Mueller-Hinton agar (Lab M Ltd., Heywood, UK) plates. Uniform wells of $7 \mathrm{~mm}$ were cut on the dried agar plate and the wells were filled with $20 \mu \mathrm{L}$ of the SaZnONPs. Zinc acetate solution, methanol extract of $S$. alata leaves, dimethyl sulfoxide (DMSO), streptomycin, and fungusol (miconazole nitrate BP 2\%; Afrab Chem Ltd, Lagos, Nigeria) were used as controls. The inoculated plates were incubated at $37^{\circ} \mathrm{C}$ for $24 \mathrm{~h}$ for bacteria and at $28^{\circ} \mathrm{C}$ for $72 \mathrm{~h}$ for fungi. Diameters of clear zones of inhibition (ZOI) around the wells were measured in millimeters. Diameters greater than $1 \mathrm{~mm}$ were considered positive after subtracting the original diameter of the cork borer $(7 \mathrm{~mm})$ from the final reading.

\section{Minimum inhibitory concentration determination of the SaZnONPs}

To determine the minimum inhibitory concentration (MIC) of the SaZnONPs, wells were bored on inoculated agar plates. The wells were filled with $20 \mu \mathrm{L}$ of different concentration (10-100\%) of the SaZnONPs. The plates were incubated appropriately at $37^{\circ} \mathrm{C}$ for $24 \mathrm{~h}$ for bacteria and at $28^{\circ} \mathrm{C}$ for $72 \mathrm{~h}$ for fungi. The zones of inhibition were then observed and recorded. The lowest concentration of the SaZnONPs that completely inhibited the growth of the test microorganism was taken as the MIC of the NPs.

\section{Optimization of production conditions for SaZnONPs phytosynthesis}

The production parameters such as incubation time (2$72 \mathrm{~h}$ ), different concentration of zinc acetate (1-20 mM) and the leaves extract $(0.2-0.8 \mathrm{~mL})$, incubation temperature $\left(28-45^{\circ} \mathrm{C}\right)$ and $\mathrm{pH}(4-13)$ for NP biosynthesis was optimized. UV-visible spectra of and the FTIR of the biosynthesized SaZnONPs were evaluated.

\section{Formulation of SaZnONPs cold cream}

The cold cream formulation was done by first preparing the oil phase and aqueous phase. To prepare the base, the oil phase was prepared by adding beeswax (10 g) to 
liquid paraffin (30 g) and the mixture was placed in a water bath $\left(90^{\circ} \mathrm{C}\right)$. For the aqueous phase preparation, borax $(0.5 \mathrm{~g})$ was dissolved in distilled water $(9.5 \mathrm{~mL})$ and heated up to $50^{\circ} \mathrm{C}$. The SaZnONPs was dissolved in the aqueous phase to form a mixture. The cold cream SaZnONPs was formulated by slowly adding the oil phase to the aqueous phase with continuous stirring until it become semisolid. The control cold cream was formulated without the addition of SaZnONPs. The formulated samples were kept for further analysis.

\section{Determination of $\mathrm{pH}$ and the viscosity of the of the formulated cream}

The $\mathrm{pH}$ of the formulated cold creams was measured using direct immersion of the electrode of $\mathrm{pH}$ meter into formulated creams. The viscosity of the formulated cold cream samples at different shear rates was done using a Brookfield viscometer DV-II+ pro (Brookfield Engineering Laboratories, Middleboro, USA) with spindle No. S-64 at $20 \mathrm{rpm}$ at $25^{\circ} \mathrm{C}$, and the analysis was done in duplicate.

\section{Determination of the antimicrobial activity of the cold cream}

The antimicrobial potential of the formulated cold cream samples was evaluated using agar well diffusion method. The test pathogens were spread on Mueller agar using sterile cotton swabs. Wells were bored in the inoculated agar plates and the formulated cream samples were introduced into the wells. Formulated cream samples without the NPs, zinc acetate solution, streptomycin, and fungusol were used as controls. The plates were incubated and the diameters of clear zones of inhibition (ZOI) around the wells were recorded in millimeters.

\section{Results and discussion}

The visual observation of the ZnONPs synthesized using the crude methanol extract of $S$. alata after $24 \mathrm{~h}$ incubation is shown in Fig. $1 \mathrm{~A}-\mathrm{C}$. The mixture turned pale brown after $24 \mathrm{~h}$ of incubation, indicating the formation of SaZnONPs.

The UV-Vis absorption spectrum of SaZnONPs is shown in Fig. 2. The absorption spectrum was recorded for the NPs in the range of 200-800 $\mathrm{nm}$. The surface plasmon resonance (SPR) peak was observed at $400 \mathrm{~nm}$ after $24 \mathrm{~h}$.

The absorption spectrum of SaZnONPs $400 \mathrm{~nm}$ may be ascribed to the nanometric size effect of the synthesized $\mathrm{ZnO}$, which is characteristic of hexagonal $\mathrm{ZnONPs} .{ }^{24}$ The SPR peak of $370 \mathrm{~nm}$ has been reported by different researchers. ${ }^{21,25,26}$ This absorption peak shows evidently the monodispersion of the SaZnONPs formed. The sharp and prominent absorption band may arise due to the transitions from a valence band to conduction band.

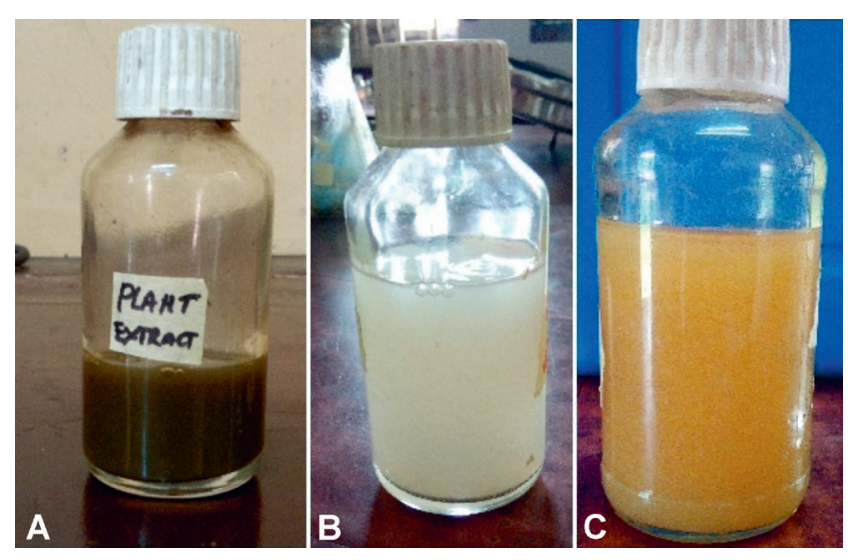

Fig. 1. Visual observation of photosynthesized SaZnONPs. A. Senna alata crude methanol leaf extract. B; Zinc acetate. C; Biosynthesized ZnONPs

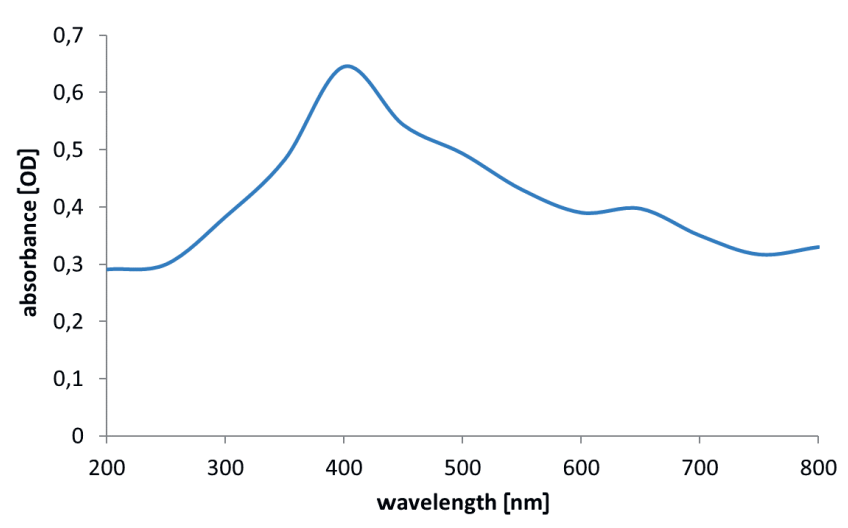

Fig. 2. UV-Vis spectra of photosynthesized SaZnONPs

The spectra of the biosynthesized SaZnONPs characterized using FTIR are shown in Fig. 3. Twelve peaks were observed - from $3852.04 \mathrm{~cm}^{-1}$ to $464.73 \mathrm{~cm}^{-1}$. The FTIR spectrum showed a broad peak at $3444.43 \mathrm{~cm}^{-1}$, which corresponds to the stretching vibrations of hydroxyl $\mathrm{OH}$ band. The peak at $2075.73 \mathrm{~cm}^{-1}$ indicates an alkyne $\mathrm{C} \equiv \mathrm{C}$ bending vibration. The peaks at $1643.73 \mathrm{~cm}^{-1}$ and $1633.71 \mathrm{~cm}^{-1}$ showed the stretching vibrations of cyclic and conjugated alkenes $(\mathrm{C}=\mathrm{C})$ group. Furthermore, the peaks at $3852.04 \mathrm{~cm}^{-1}$ and $1416.09 \mathrm{~cm}^{-1}$ indicate the presence of alcohol $(\mathrm{O}-\mathrm{H})$ group. The peak at $1650.78 \mathrm{~cm}^{-1}$ indicates the presence of phosphine $(\mathrm{X}=\mathrm{C}=\mathrm{Y})$ groups. The band at $1011.78 \mathrm{~cm}^{-1}$ corresponds to the bending vibration of the alkyl aryl ether $(\mathrm{C}-\mathrm{O})$, while the peak at $569.06 \mathrm{~cm}^{-1}$ shows the presence of an alkyl halides (C-X) group. Finally, the band at $464.73 \mathrm{~cm}^{-1}, 651.76 \mathrm{~cm}^{-1}$ and $716.56 \mathrm{~cm}^{-1}$ corresponds to the stretching of $\mathrm{Zn}-\mathrm{O}$ compound.

The FTIR results show the possible plant biomolecules involved in the NP biosynthesis and as functioning capping agents. It also shows that the biosynthesized SaZnONPs were surrounded by proteins and other metabolites. ${ }^{27}$ Based on the FTIR spectra, it can be stated that the presence of these functional groups suggests that the biological molecules play an important role in the biosynthesis of NPs, and could possibly perform dual functions of formation and stabilization of SaZnONPs in an aqueous medium. 


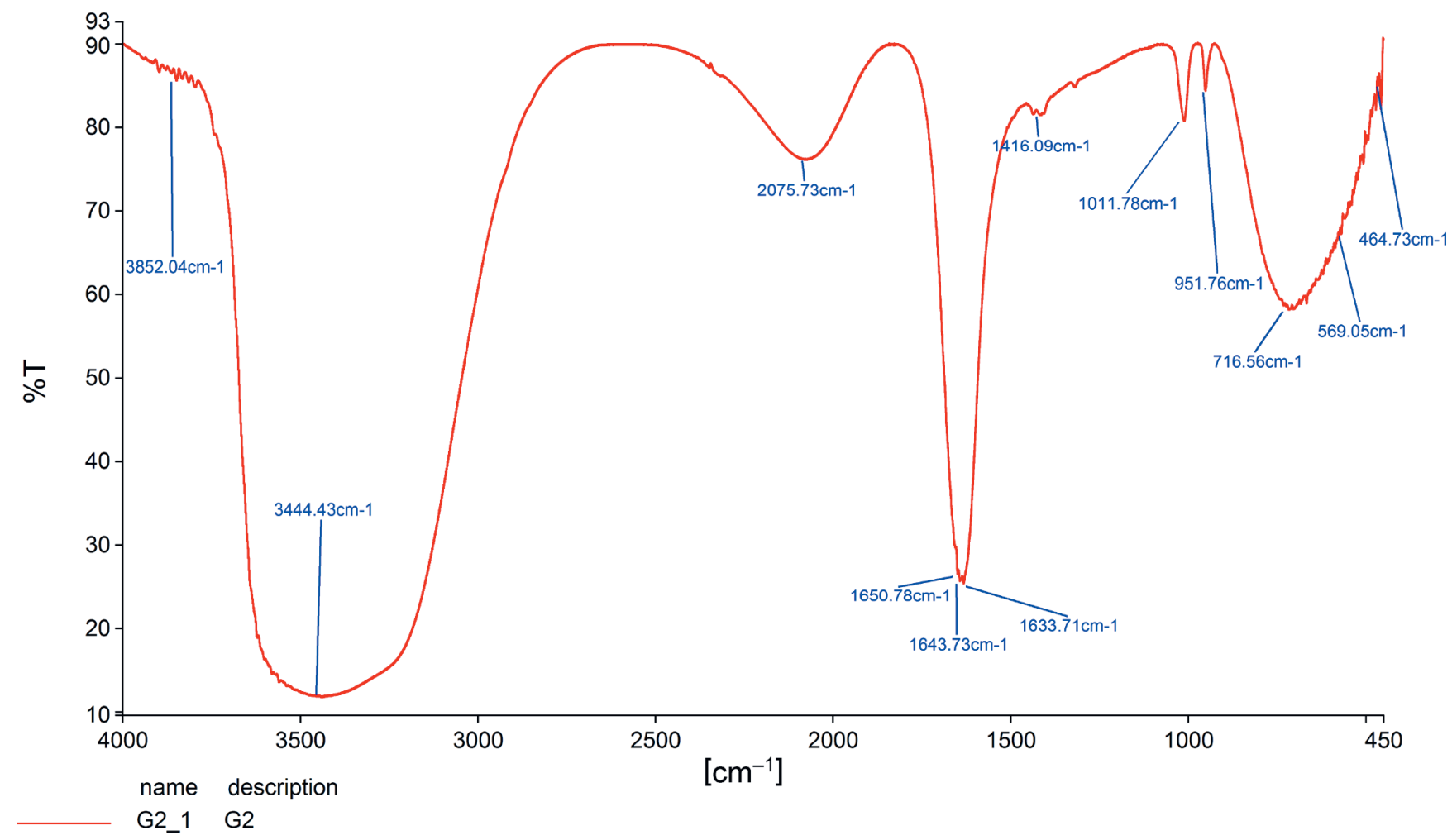

Fig. 3. FTIR spectra of SaZnONPs

The SEM image of SaZnONPs is presented in Fig. 4. It shows needle-like shape NPs with $10.3 \mathrm{~nm}$ in diameter.
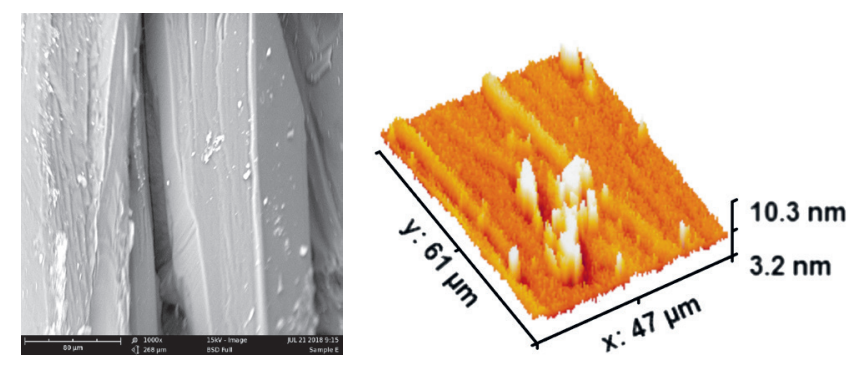

Fig. 4. SEM image of SaZnONPs

The SEM images of the crystals showed some non-uniform distribution in the form of a needle-like structure without agglomeration. The boundaries between single crystallites were visible. Agglomerates were composed of several individual nano-sized crystals.

The TGA of SaZnONPs is showed in Fig. 5. The TGA profile showed a continuous weight loss with 2 quasisharp changes occurring at $234.02^{\circ} \mathrm{C}$ and $473.75^{\circ} \mathrm{C}$, followed by a nearly constant plateau. The annealing above $473.75^{\circ} \mathrm{C}$ seems to guarantee the formation of stable SaZnONPs. After heating to $234.02^{\circ} \mathrm{C}$, the excess water seems to be driven off and the material initiates organic carbon decomposition. The material continues to decompose. Oxidation of the catalyst particles is seen after $473.75^{\circ} \mathrm{C}$, leading to dramatic mass changes with a residual mass of $4.95 \%$ at $846.87^{\circ} \mathrm{C}$.
The TGA showed a two-stage weight loss, which indicates the decomposition and vaporization of various functional groups at different temperatures. The large weight loss may be attributed to the breakdown of the organic carbon coordinated with ZnONPs in extract-zinc acetate hybrid. Oxidation of the catalyst particles is seen after $473.75^{\circ} \mathrm{C}$, leading to dramatic mass changes with a residual mass of $4.95 \%$ at $846.87^{\circ} \mathrm{C}$. This report differs from the observation of Ramesh et al., ${ }^{27}$ who observed thermal dehydration at $165^{\circ} \mathrm{C}$ and $318^{\circ} \mathrm{C}$ respectively, with an endothermic peak at $390^{\circ} \mathrm{C}$ during the decomposition of zinc nitrate to $\mathrm{ZnO}$.

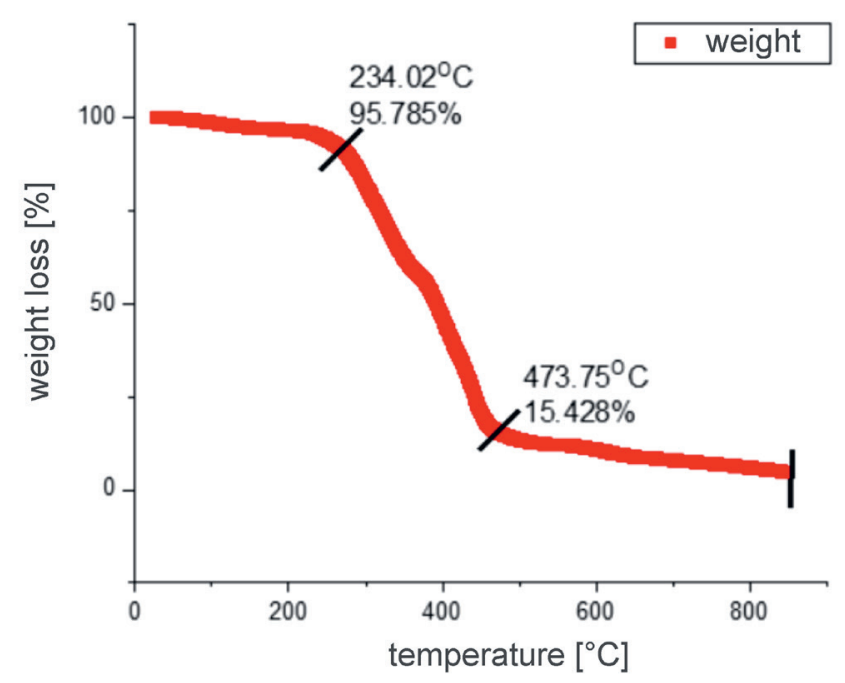

Fig. 5. The results of TGA of SaZnONPs 
The TGA shows the interaction between the NPs and the stabilizer. Singh et al. ${ }^{28}$ reported that the TGA of NPs and of capping agents not only provides information about the stability of NPs, but can also evaluate the yield of NPs in the final product.

Figure 6 shows the average particle size, size distribution, and polydispersity index (PDI) of SaZnONPs using DLS measurement. It shows average particle sizes of $412.0 \mathrm{~nm}$ and $155.2 \mathrm{~nm}$ with a polydispersity index of 0.481 .

The hydrodynamic diameter, which uses the diffusion coefficient of the SaZnONPs colloids and the autocorrelation function measured with DLS techniques, showed the size and distribution of the NPs. The large average diameter of $549.2 \mathrm{~nm}$ can be attributed to the aggregation of the NPs over time. This is in line with the work of Chitsazi et al., who observed that there was an increase in the average diameter of synthesized NPs with an increase in reaction time. ${ }^{29}$

The EDX spectrum of the biosynthesized SaZnONPs is shown in Fig. 7. The spectrum of the optimized sample confirmed the presence of zinc and oxygen in the powder. Consequentially, there are no other elements except zinc, thereby sustaining the pure chemical form of the formed ZnONPs.

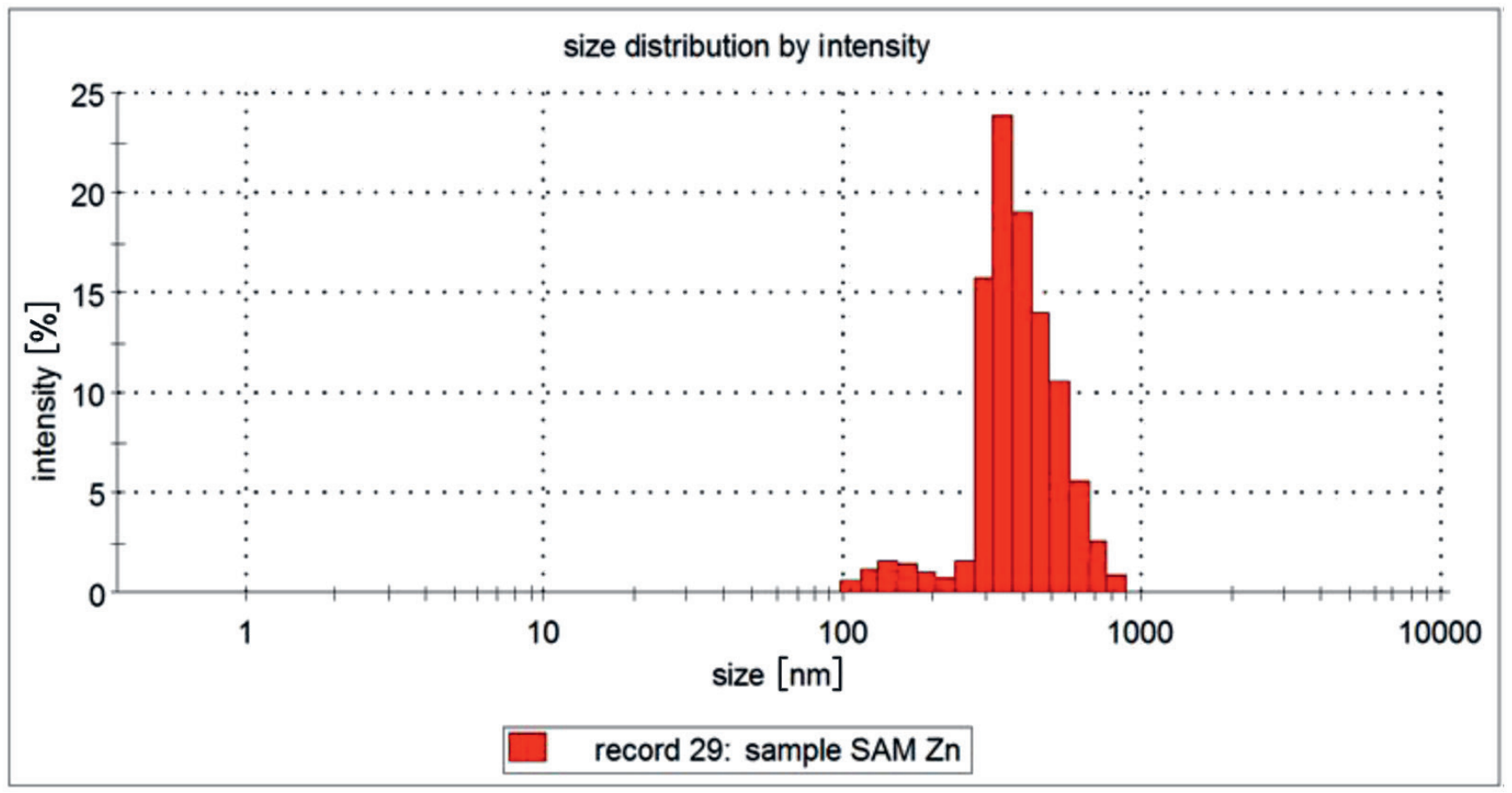

Fig. 6. DLS showing the particle size distribution of SaZnONPs

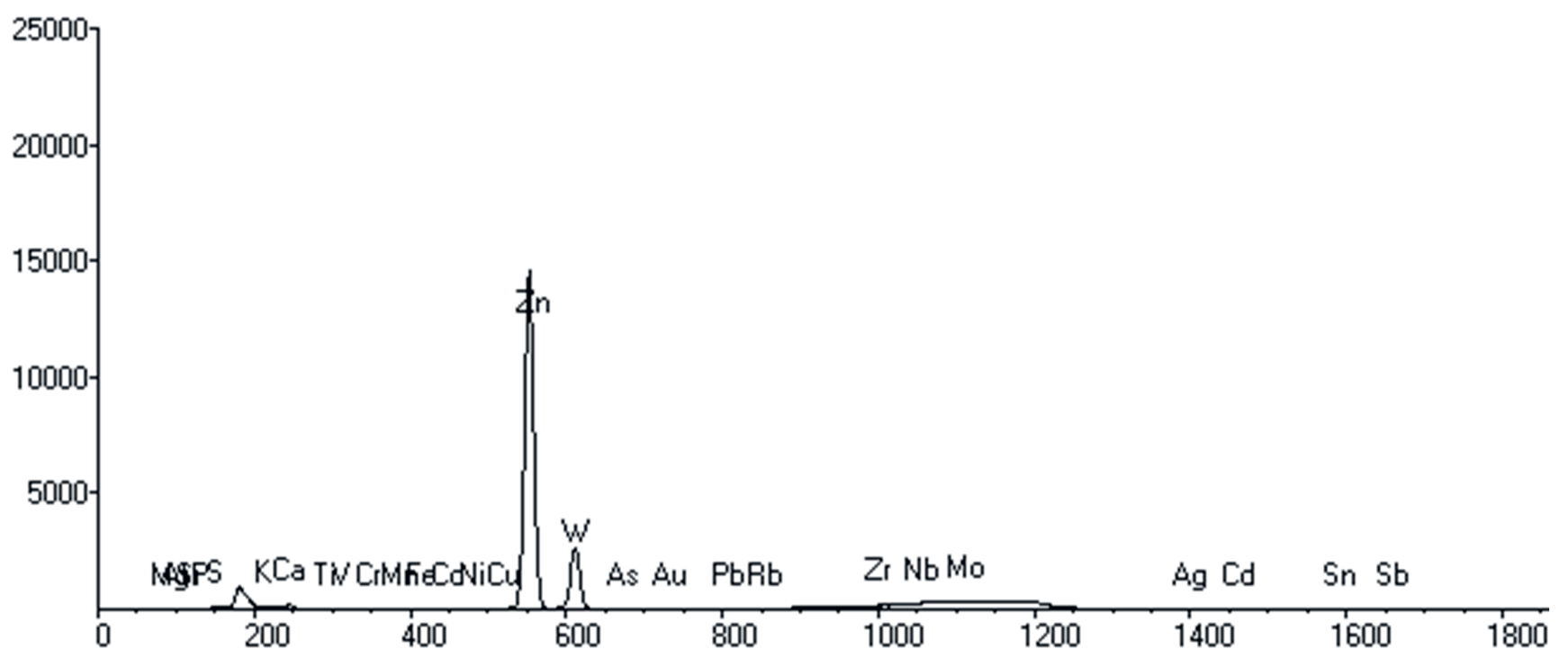

Fig. 7. EDX spectra of SaZnONPs 
Figure 8 shows the results of XRD analysis of the SaZnONPs. It was observed that the 7 reflection peaks of $2 \theta$ degree with corresponding Miller indices (hkl) showed values at $15.32^{\circ}(002), 37.39^{\circ}(110), 40.58^{\circ}(002), 42.15^{\circ}$ (101), $43.09^{\circ}(101), 44.18^{\circ}(002)$, and 46.99 (101), which are matched with the Crystallography Open Database (COD; http://www.crystallography.net/cod) in MATCH! Phase Identification (https://www.crystalimpact.com/match) from Powder Diffraction software.

The EDX spectrum of SaZnONPs sample confirmed the presence of zinc in the powder. The EDX clearly showed the purity of biosynthesized metal NPs and of the SaZnONPs. ${ }^{30}$

The antifungal potential and MIC of the SaZnONPs against pathogenic fungi is shown in Table 1 . The SaZnONPs presented activity only against Pichia sp. and T. interdigitale with a zone of $16 \mathrm{~mm}$ and $11 \mathrm{~mm}$, respectively, while the remaining fungi strain were resistant. The activity of the SaZnONPs against Pichia sp. and T. interdigitale was up to $10 \%$, showing that the 2 organisms are highly susceptible to SaZnONPs.

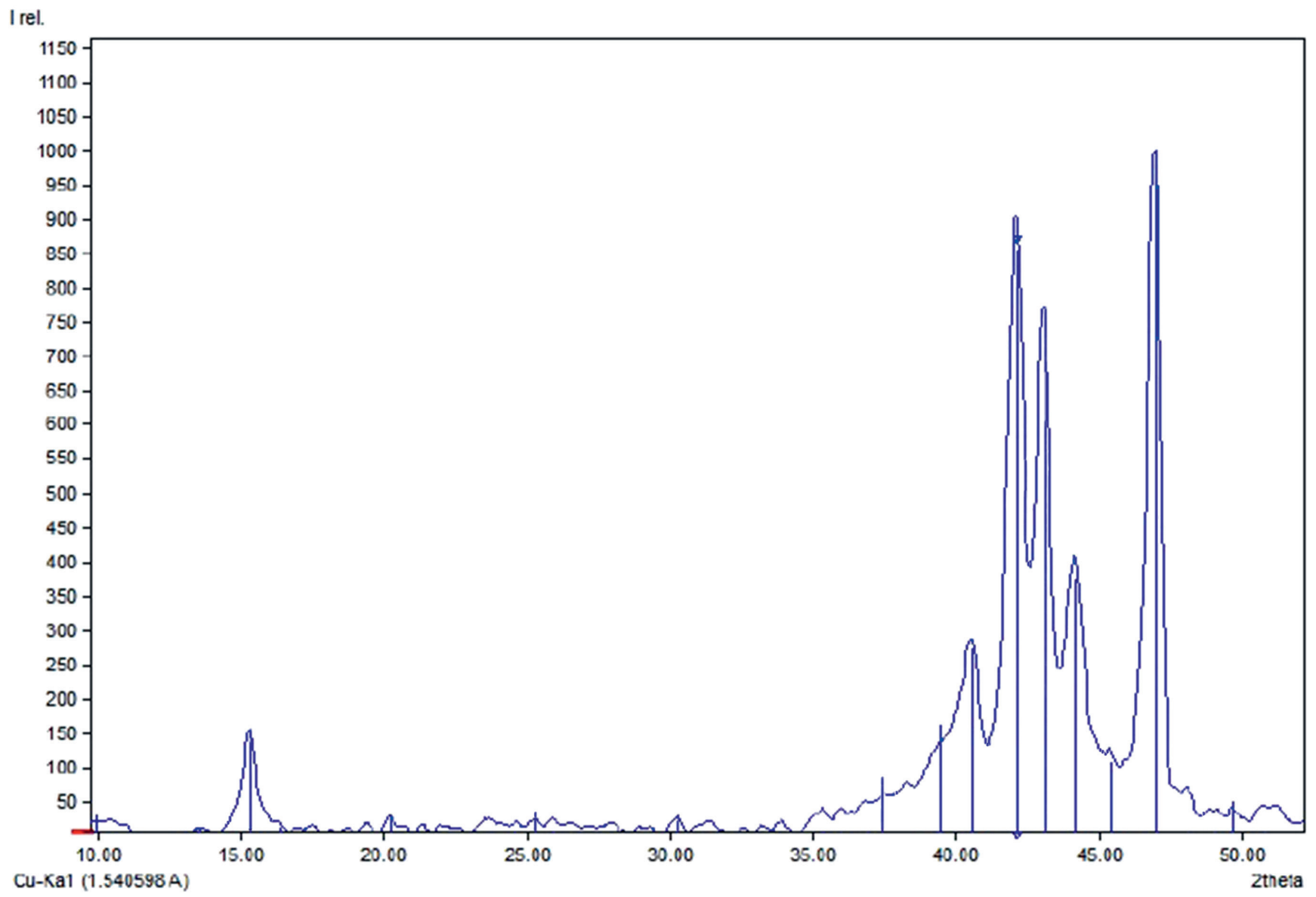

Fig. 8. XRD pattern of SaZnONPs

Table 1. Antifungal activity and MIC of SaZnONPs against some pathogenic fungi

\begin{tabular}{|c|c|c|c|c|c|c|c|c|c|}
\hline \multirow{3}{*}{ Test bacteria } & \multicolumn{3}{|c|}{ Antibacterial activity [mm] } & \multirow{2}{*}{\multicolumn{6}{|c|}{$\frac{\text { MIC for SaZnONPs [\%] }}{\text { zone of inhibition [mm] }}$}} \\
\hline & \multirow{2}{*}{ SaZnONPs } & \multirow{2}{*}{ zinc acetate solution } & \multirow{2}{*}{ fungusol } & & & & & & \\
\hline & & & & 100 & 90 & 70 & 50 & 30 & 10 \\
\hline C. albicans A & - & - & 2 & - & - & - & - & - & - \\
\hline C. albicans B & - & - & 6 & - & - & - & - & - & - \\
\hline C. albicans $C$ & - & - & 8 & - & - & - & - & - & - \\
\hline Rhizopus sp. & - & - & 4 & - & - & - & - & - & - \\
\hline Pichia sp. & 16 & 6 & 8 & 16 & 16 & 14 & 12 & 10 & 8 \\
\hline C. tropicalis & - & - & 4 & - & - & - & - & - & - \\
\hline C. krusei & - & - & 2 & - & - & - & - & - & - \\
\hline T. interdigitale & 11 & 4 & 6 & 11 & 15 & 14 & 12 & 8 & 8 \\
\hline
\end{tabular}

SaZnONPs - zinc oxide nanoparticles biosynthesized using crude methanol leaf extract of Senna alata; MIC - minimum inhibitory concentration. 
The antibacterial activity and MIC of the SaZnONPs against pathogenic bacteria is shown in Table 2. The SaZnONPs presented activity against $S$. aureus D E. coli 35218, S. saprophyticus B and S. epidermidis C with zone of inhibition of $9 \mathrm{~mm}, 5 \mathrm{~mm}$ and $2 \mathrm{~mm}$, respectively. The SaZnONPs had a low activity $(1.00 \mathrm{~mm})$ against $S$. aureus $\mathrm{D}$ at $10 \%$ concentration, while there was no activity recorded against it for S. saprophyticus B and S. epidermidis $\mathrm{C}$ beyond the full $100 \%$ concentration of the SaZnONPs.

The SaZnONPs showed activity against only 2 of the fungi species. Rajiv et al. observed that plant pathogenic fungi were susceptible to ZnONPs. ${ }^{21}$ The susceptibility of tested fungi pathogens can be attributed to the nature of the particles, i.e., their nanoscale structure. ${ }^{31}$ The SaZnONPs showed activity against different species of Staphylococcus and against E. coli 3521. Gunalan et al. ${ }^{10}$ observed that $\mathrm{ZnONPs}$ were active against $S$. aureus, while Ambika and Sundrarajan ${ }^{24}$ recorded antibacterial activity against $S$. aureus and E. coli. Gunalan et al. revealed that the nanosize of NPs enables the permeability of bacteria cell membrane and gives access to the organelles of the cell. ${ }^{10}$

The MIC of the NPs against both the fungi and bacteria pathogens showed a continuous decrease in activity along with the reduction in the concentration of the NPs used. This showed that the activity of the NPs depends on its concentration. This is in accordance with the report of Dubey et al. ${ }^{32}$ and Oboh and Abulu ${ }^{33}$ who stated that antimicrobial activity is a function of the concentration of the active ingredient that is in contact with the organism.

Optimization of conditions of different production parameters on the biosynthesis of ZnONPs was investigated. Figure 9A shows the UV-Vis spectra during op- timization of incubation time $(2-72 \mathrm{~h})$ on the biosynthesis of SaZnONPs. The optimum incubation time for the biosynthesis was recorded at $24 \mathrm{~h}$. The SPR shows a high sharp peak after $24 \mathrm{~h}$ of synthesis at a wavelength of $400 \mathrm{~nm}$.

Figure 9B shows the UV-Vis spectra during optimization of SaZnONPs biosynthesis at different molar concentration of zinc acetate; $10 \mathrm{mM}$ supported the optimum SaZnONPs biosynthesis. The SPR showed a sharp peak at $400 \mathrm{~nm}$ for $10 \mathrm{mM}$ zinc acetate molar concentration. Broad peaks were observed for other concentrations at $500 \mathrm{~nm}$.

Figure 10A shows the UV-Vis spectra during optimization of different incubation temperature $\left(4-45^{\circ} \mathrm{C}\right)$ for the biosynthesis of SaZnONPs. The temperature of $4^{\circ} \mathrm{C}$ supported optimum SaZnONPs production and the SPR was recorded at $600 \mathrm{~nm}$.

Figure 10B shows the UV-Vis spectra for optimization of SaZnONPs biosynthesized using different volume of the extract $(0.2-0.8 \mathrm{~mL}) .0 .8 \mathrm{~mL}$ of the extract supported optimum SaZnONPs biosynthesis. The SPR showed peaks was at $450 \mathrm{~nm}$.

Figure 11 shows the UV-Vis spectra for optimization of $\mathrm{pH}$ (4-13) for biosynthesis of SaZnONPs. pH 13 supported optimum biosynthesis with SRP at $450 \mathrm{~nm}$.

It is well known that the morphology and size of metal NPs produced from a metallic precursor in a solution depend on various reaction conditions, such as the concentration of metal ion, ratio of metallic salt/reducing agent, time, temperature, and $\mathrm{pH} .{ }^{34}$ The optimization of conditions for SaZnONPs synthesis in this study indicated the effect of the different parameters - time, temperature,

Table 2. Antibacterial activity and MIC of SaZnONPs against some pathogenic bacteria

\begin{tabular}{|c|c|c|c|c|c|c|c|c|c|}
\hline \multirow{3}{*}{ Test bacteria } & \multicolumn{3}{|c|}{ Antibacterial activity [mm] } & \multirow{2}{*}{\multicolumn{6}{|c|}{$\begin{array}{c}\text { MIC for SaZnONPs [\%] } \\
\text { Zone of inhibition [mm] }\end{array}$}} \\
\hline & \multirow{2}{*}{ SaZnONPs } & \multirow{2}{*}{ zinc acetate solution } & \multirow{2}{*}{ streptomycin } & & & & & & \\
\hline & & & & 100 & 90 & 70 & 50 & 30 & 10 \\
\hline S. aureus A & - & - & 8.00 & - & - & - & - & - & - \\
\hline S. aureus B & - & - & 9.50 & - & - & - & - & - & - \\
\hline S. aureus C & - & - & 12.50 & - & - & - & - & - & - \\
\hline S. aureus D & 9 & - & 12.00 & 9 & 10 & 8 & 8 & 5 & 1 \\
\hline S. aureus 29213 & - & - & 7.00 & - & - & - & - & - & - \\
\hline E. coli 35218 & 5 & 4 & 7.00 & 5 & - & - & - & - & - \\
\hline E. coli 11775 & - & - & 6.50 & - & - & - & - & - & - \\
\hline P. aeruginosa 27853 & - & - & 7.00 & - & - & - & - & - & - \\
\hline C. freundii & - & - & 8.00 & - & - & - & - & - & - \\
\hline S. typhi 14028 & - & - & 7.00 & - & & - & - & - & - \\
\hline B. cereus & - & - & 7.50 & - & - & - & - & - & - \\
\hline S. saprophyticus A & - & - & 8.50 & - & - & - & - & - & - \\
\hline S. saprophyticus B & 2 & - & 8.00 & 2 & - & - & - & - & - \\
\hline S. epidermidis A & - & - & 8.00 & - & - & - & - & - & - \\
\hline S. epidermidis B & - & - & 8.00 & - & - & - & - & - & - \\
\hline S. epidermidis C & 2 & 2 & 6.50 & 2 & - & - & - & - & - \\
\hline
\end{tabular}



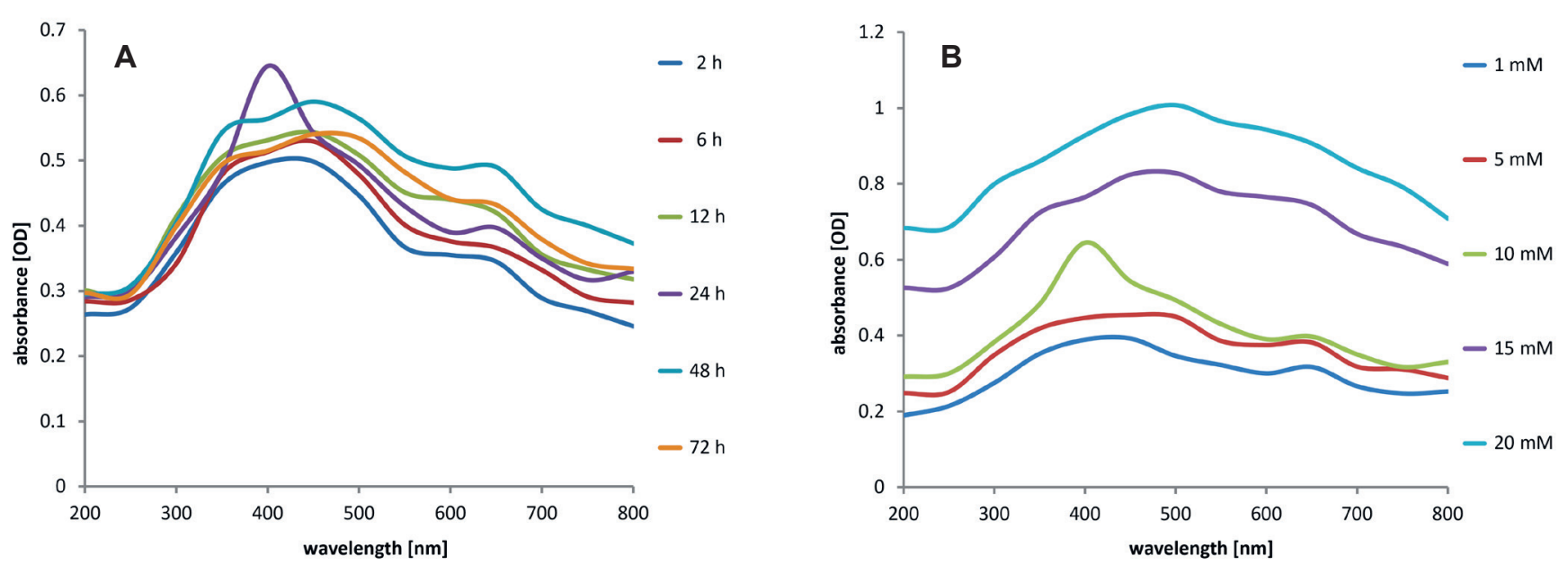

Fig. 9. UV-Vis spectra of the SaZnONPs biosynthesized at different (A) incubation time and (B) molar concentrations of zinc acetate
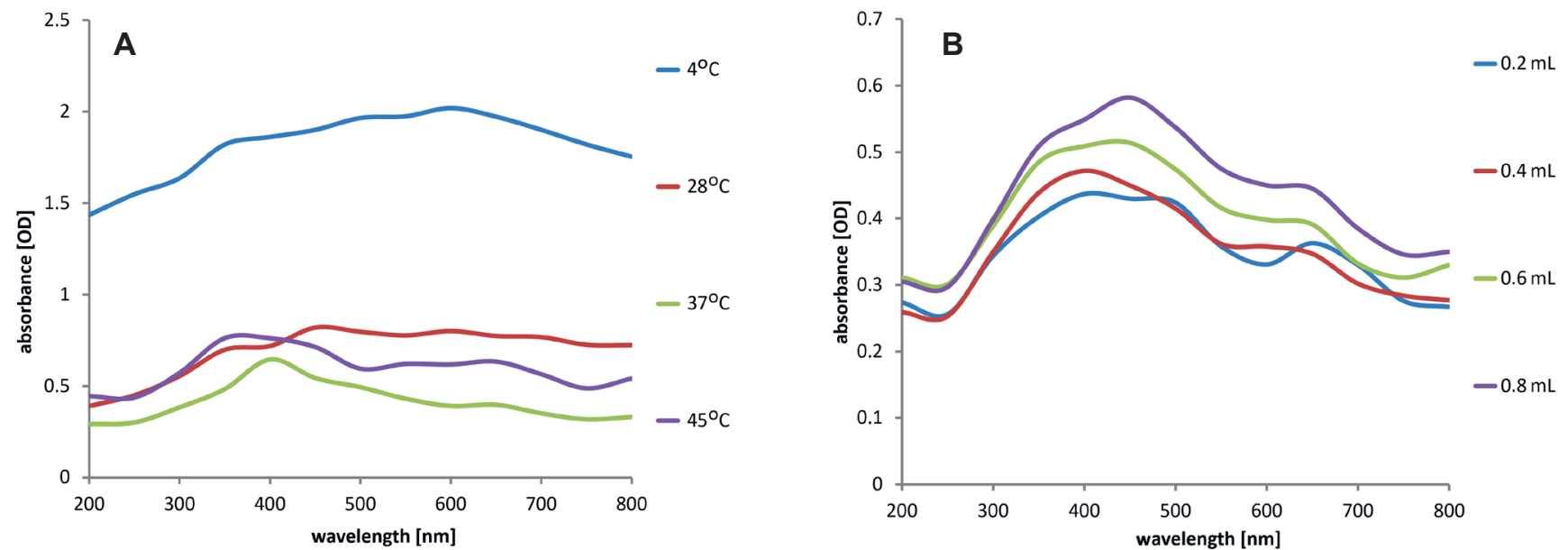

Fig. 10. UV-Vis spectra of the SaZnONPs biosynthesized at (A) different incubation temperature and (B) different concentration of the extract

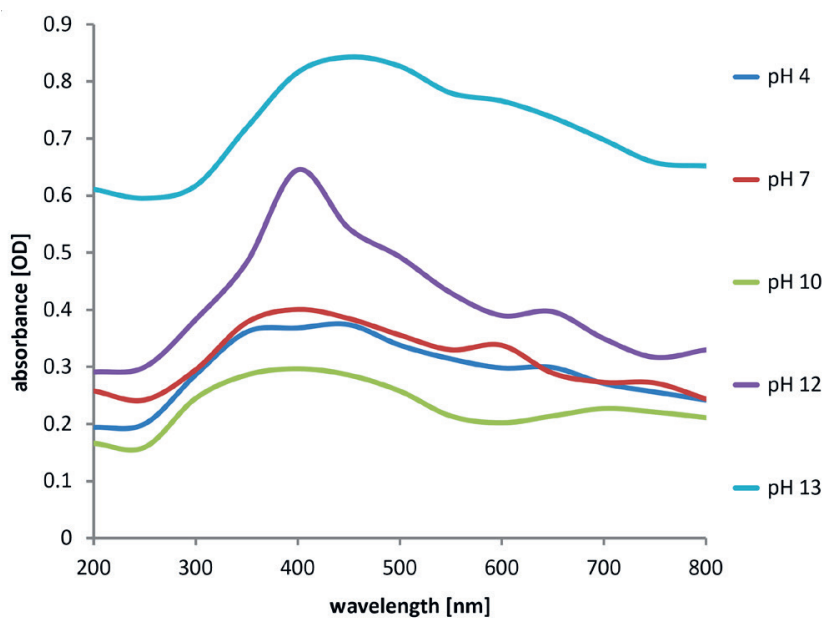

Fig. 11. UV-Vis spectra of the SaZnONPs biosynthesized at different $\mathrm{pH}$

concentrations of zinc salt and extract, and $\mathrm{pH}$ on the NPs phytosynthesis. The effect of time is a significant factor that affects production of SaZnONPs. The SPR was recorded after $24 \mathrm{~h}$ which is a period considered being enough for the maximal production of SaZnONPs. This finding was in contrast with the report of Raliya and
Tarafdar, ${ }^{29}$ where it was observed that the biosynthesis of $\mathrm{ZnONPs}$ was optimal after $72 \mathrm{~h}$ of incubation. The incubation temperature of $4^{\circ} \mathrm{C}$ showed the highest plasmon peak of the biosynthesis of SaZnONPs while the SPR was observed using $10 \mathrm{mM}$ of zinc acetate. Different volume of $S$. alata leaf extracts were used for the synthesis of SaZnONPs, and $0.8 \mathrm{~mL}$ of the extract was most suitable. These results also indicate that basic $\mathrm{pH}$ had the highest peak during SaZnONPs biosynthesis. A sharp peak was recorded at $\mathrm{pH}$ 12. $\mathrm{pH}$ affects the amount of NPs production and their stability, which is a critical factor in the control of the size and morphology of NPs. ${ }^{35}$

Figures 12-15 show shows the FTIR spectra of the different optimized conditions for the biosynthesis of SaZnONPs. Five troughs corresponding to the hydroxyl $\mathrm{O}-\mathrm{H}$ stretching bonds, alkynes and amides were prominent in all the spectra.

The FTIR spectra under different optimization conditions showed that the peaks around $3400 \mathrm{~cm}^{-1}$ and $1600 \mathrm{~cm}^{-1}$, which corresponds to the $\mathrm{O}-\mathrm{H}$ stretch and $\mathrm{C}=\mathrm{C}$ stretch, were constant under all conditions. This shows that under different optimization conditions, there are large amounts of compounds that can actively chelate 


\section{SaZnONPs}

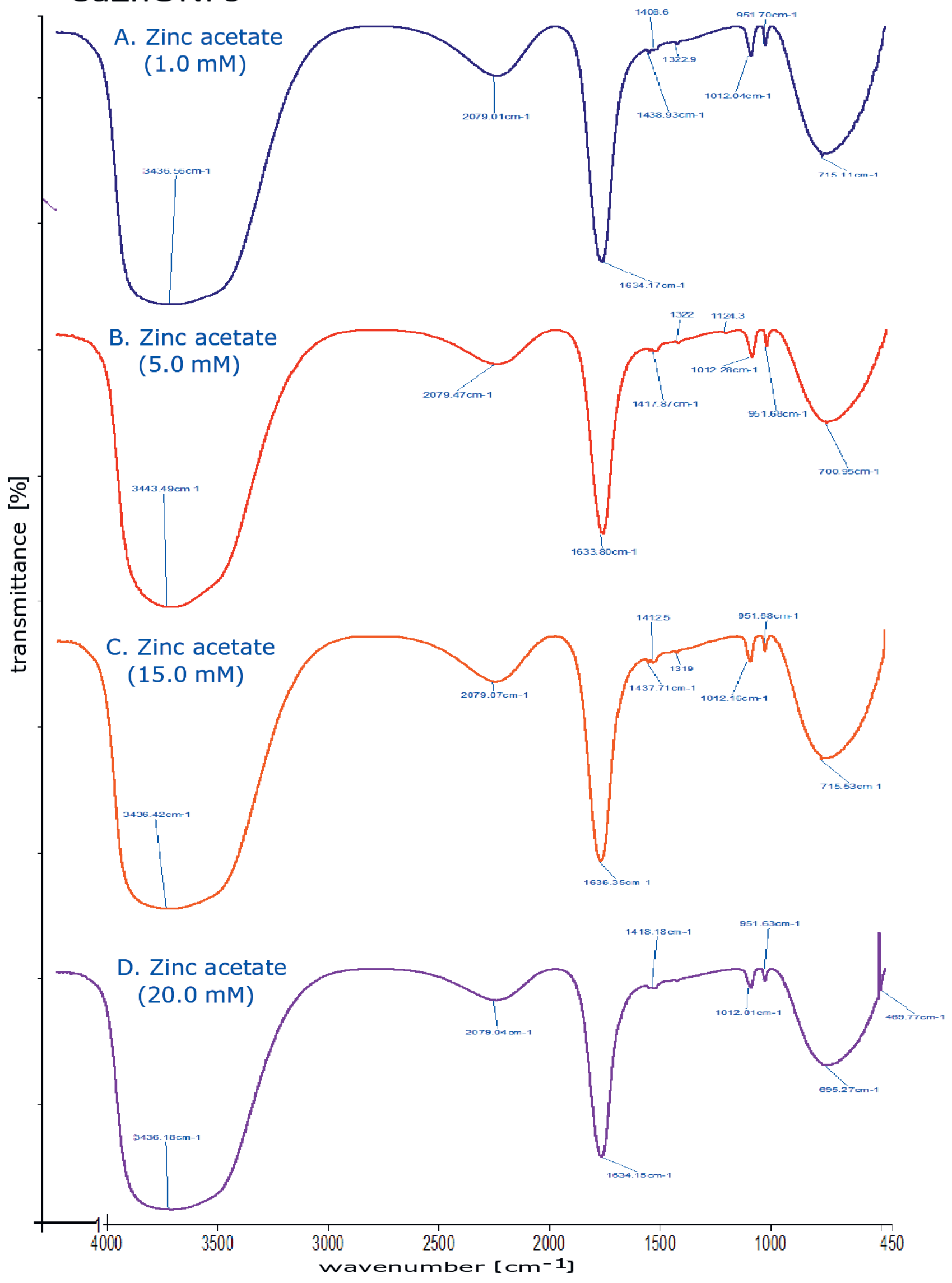

Fig. 12. FTIR spectra of SaZnONPs biosynthesized under optimized concentration of zinc acetate: A) $0.1 \mathrm{mM}$ zinc acetate; B) $5.0 \mathrm{mM}$ zinc acetate; C) 15.0 mM zinc acetate; and D) $20.0 \mathrm{mM}$ zinc acetate 
and reduce the NPs, which is confirmed in the fingerprint regions of the latter end of the spectrum. The effect of different parameters could have inhibited the activity of some of the components of the plant extract, as seen in the absence of some functional groups under different conditions. The biological entities act as capping and stabilizing agents in the synthesis process. Good examples are the phytochemicals like flavonoids, phenolics, terpenoids, and cofactors, which act mainly as reducing and stabilizing agents during synthesis.

\section{SaZnONPs}

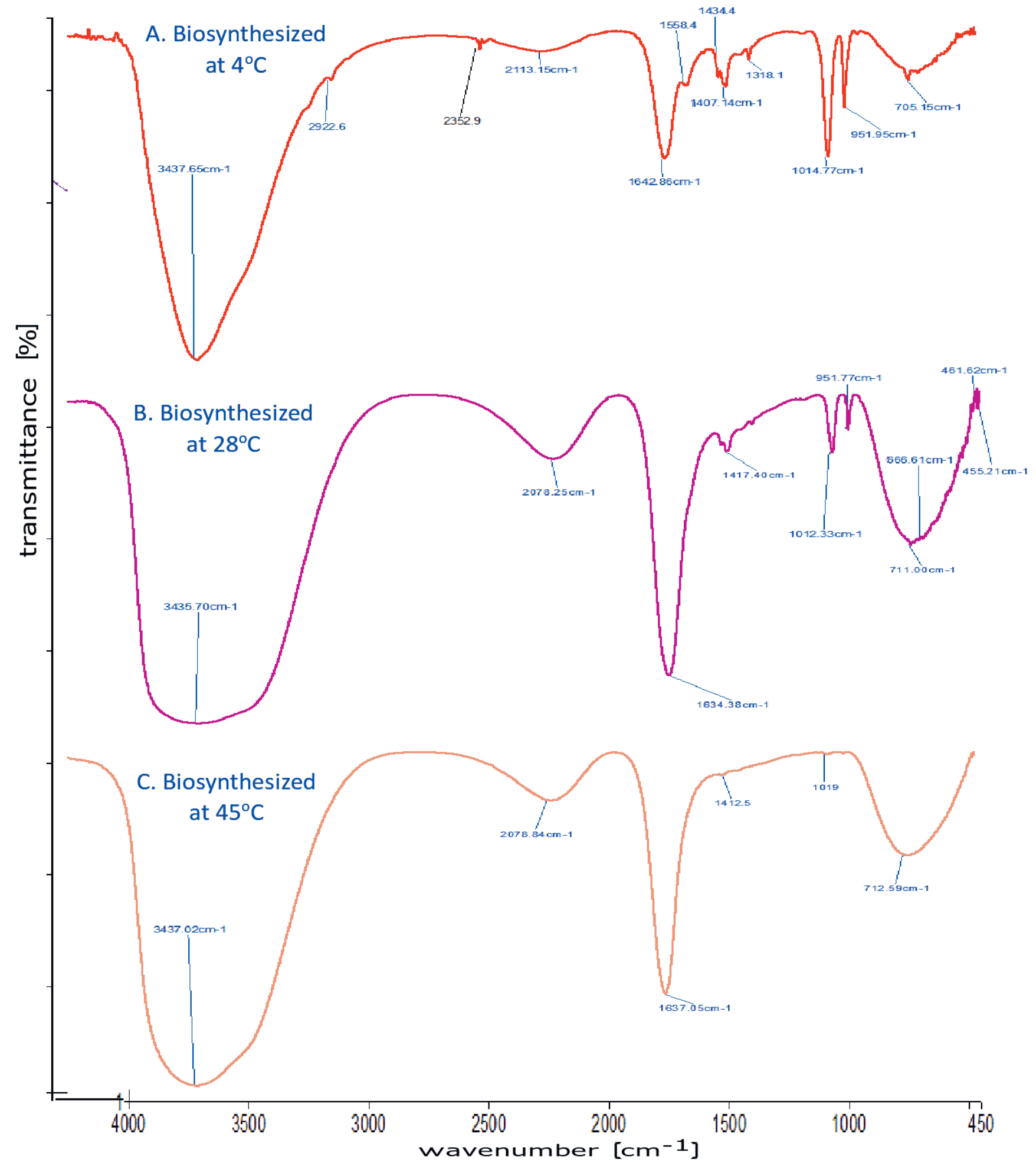

Fig. 13. FTIR spectra of SaZnONPs biosynthesized under optimized temperature: A) $4^{\circ} \mathrm{C}$; B) $28^{\circ} \mathrm{C}$; and $\left.\mathrm{C}\right) 45^{\circ} \mathrm{C}$ 


\section{SaZnONPs}

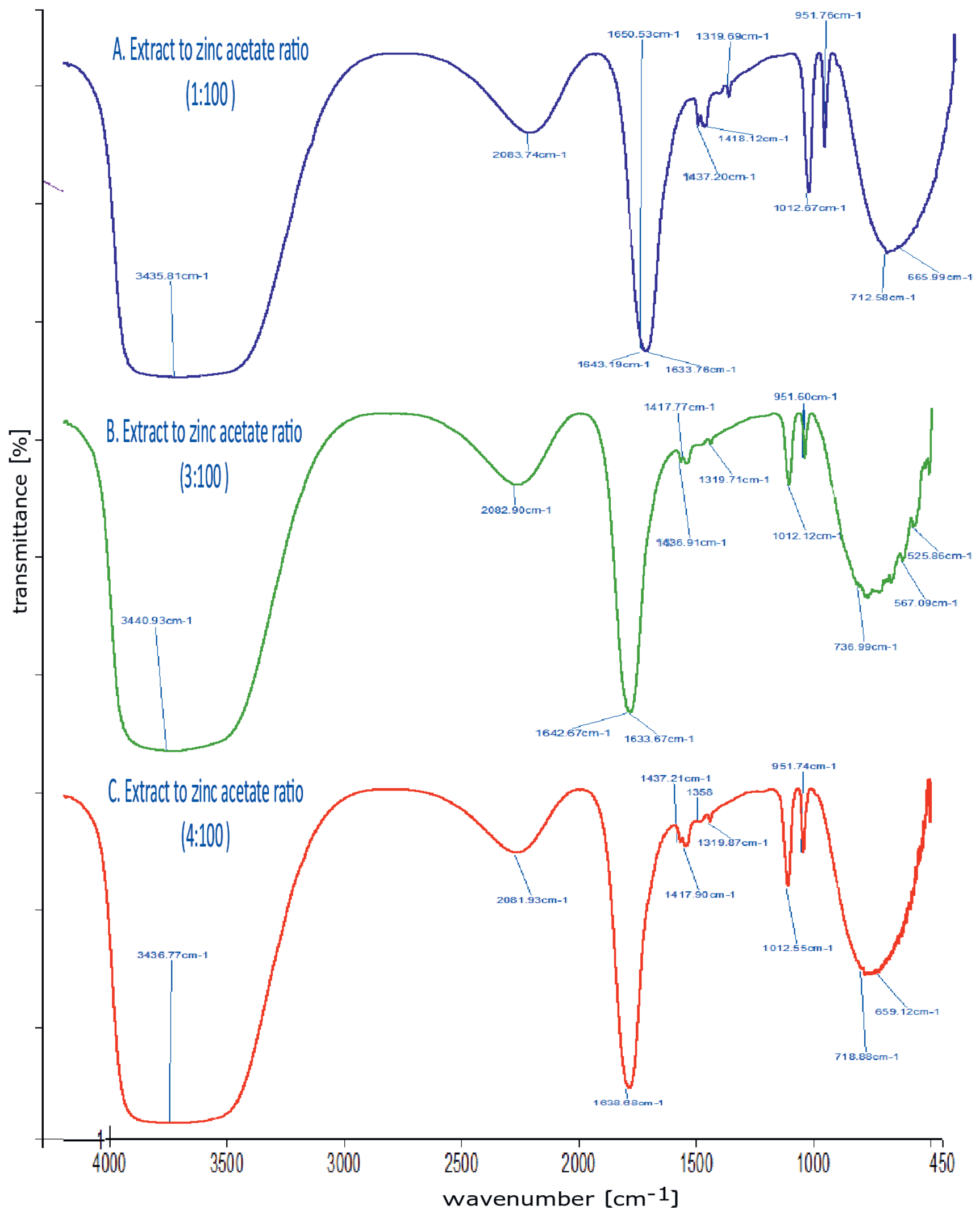

Fig. 14. FTIR spectra of SaZnONPs biosynthesized under optimized extract to zinc acetate ratio: A) 1:100; B) 3:100; and C) 4:100 
SaZnONPs

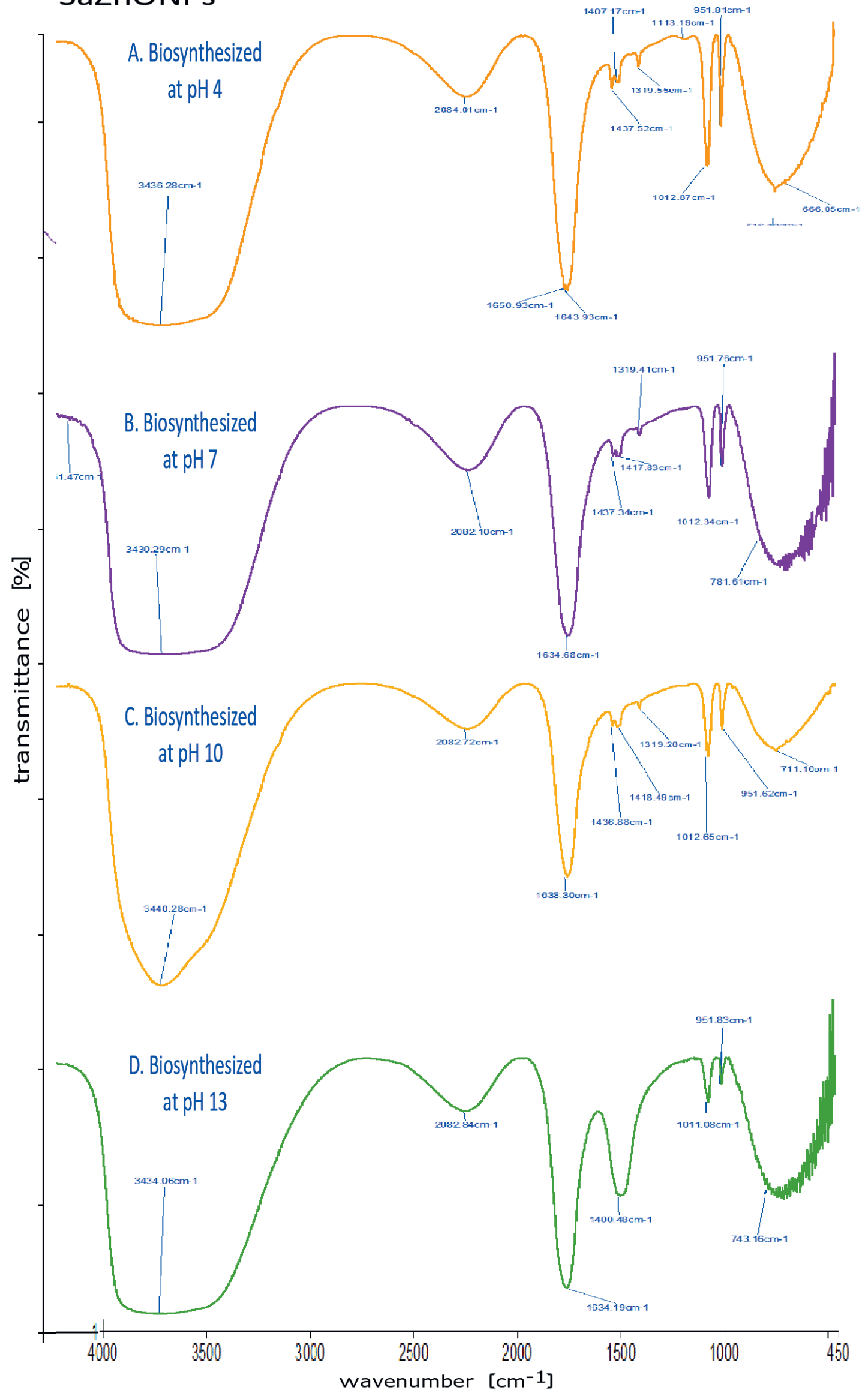

Fig. 15. FTIR spectra of SaZnONPs biosynthesized under optimized pH: A) pH 4; B) pH 7; C) pH 10; and D) pH 13 
Table 3 shows the viscosity and $\mathrm{pH}$ measurement of the cold cream incorporated with $1 \%$ SaZnONPs (C1) and cold cream combined with $2 \%$ SaZnONPs (C2). The viscosity was reported in a unit of centipoises (cps) and torque. The apparent viscosity and torque were shown in relation to the revolutions per minute (rpm or shear stress) for the formulations. The viscosity for the $\mathrm{C} 1$ and C2 formulated cold cream samples were $14,400 \mathrm{cps}$ and $12,240 \mathrm{cps}$ at $50 \mathrm{rpm}$ and $8080 \mathrm{cps}$ and $6920 \mathrm{cps}$ at $100 \mathrm{rpm}$, respectively.

The $\mathrm{pH}$ of the cream base was 5.64, while the $\mathrm{pH}$ of the $\mathrm{C} 1$ and $\mathrm{C} 2$ samples were 8.16 and 7.56. There was an increase in $\mathrm{pH}$ when $1 \%$ and $2 \%$ SaZnONPs was incorporated into the cream base.

Table 4 shows the antibacterial and antifungal activity of cold cream incorporated with SaZnONPs against the test pathogen. Only 1 strain of $S$. aureus was susceptible

Table 3. Viscosity and $\mathrm{pH}$ values of the different cream formulations

\begin{tabular}{|c|c|c|c|c|c|}
\hline \multirow{3}{*}{ Sample code } & \multicolumn{4}{|c|}{ Viscosity } & \multirow{3}{*}{$\mathrm{pH}$} \\
\hline & \multicolumn{2}{|c|}{$50 \mathrm{rpm}$} & \multicolumn{2}{|c|}{$100 \mathrm{rpm}$} & \\
\hline & centipoise & torque & centipoise & torque & \\
\hline $\mathrm{Cl}$ & 14,400 & 18.05 & 8080 & 20.2 & 8.16 \\
\hline $\mathrm{C} 2$ & 12,240 & 15.3 & 6920 & 17.3 & 7.56 \\
\hline $\mathrm{C3}$ & - & - & 7560 & - & 6.92 \\
\hline Cream base & - & - & 3160 & - & 5.64 \\
\hline
\end{tabular}

C1 - cold cream incorporated with 1\% SaZnONPs;

C2 - cold cream incorporated with $2 \%$ SaZnONPs;

C3 - cold cream incorporated with $2 \%$ zinc acetate. to the formulated cream with a $3.0 \mathrm{~mm}$ zone of inhibition. The cream showed activity against $25 \%$ (2) of the fungal pathogens - Pichia sp. $(2.0 \mathrm{~mm})$ and T. interdigitale $(5.0 \mathrm{~mm})$.

The $\mathrm{pH}$ of the human skin typically ranges from 4.5 to 6.0 , and 5.5 is considered to be the average $\mathrm{pH}$ of the skin. ${ }^{36}$ Therefore, the formulations intended for application to the skin should have $\mathrm{pH}$ close to this range. In this study, all the cream formulations were close to the $\mathrm{pH}$ of the skin. The cream formulations also showed proper viscosity, which is needed for good cream-based formulations.

\section{Conclusions}

Senna alata methanol leaf extract was a good bioreducing, stabilizing and capping agent for zinc acetate in the phytosynthesis of SaZnONPs. The biosynthesized NPs exhibited good antibacterial and antifungal activity against some of the test pathogens. The SaZnONPs formulated cream has good viscosity and $\mathrm{pH}$ and appreciable antimicrobial efficiency against a few of the test bacteria and fungi.

\section{ORCID iDs}

Bukola Christianah Adebayo-Tayo (1) https://orcid.org/0000-0003-2404-1686

Samuel O. Borode (10) https://orcid.org/0000-0003-4929-4786

Olusola Ademola Olaniyi 10 https://orcid.org/0000-0002-5811-2270

Table 4. Antibacterial and antifungal activity of SaAgNPs-incorporated cold cream formulation

\begin{tabular}{|c|c|c|c|c|c|}
\hline $\mathrm{S} / \mathrm{N}$ & Test bacteria & $\begin{array}{l}\text { Antibacterial activity of SaZnONPs cold cream } \\
{[\mathrm{mm}]}\end{array}$ & $\mathrm{S} / \mathrm{N}$ & Test fungi & $\begin{array}{l}\text { Antifungal activity of SaZnONPs cold cream } \\
\qquad[\mathrm{mm}]\end{array}$ \\
\hline 1 & S. aureus A & 3.0 & 1 & C. albicans A & - \\
\hline 2 & S. aureus B & - & 2 & C. albicans B & - \\
\hline 3 & S. aureus C & - & 3 & C. albicans C & - \\
\hline 4 & S. aureus D & - & 4 & Rhizopus sp. & - \\
\hline 6 & E. coli 35218 & - & 6 & C. tropicalis & - \\
\hline 7 & E. coli 11775 & - & 7 & C. krusei & - \\
\hline 8 & P. aeruginosa 27853 & - & 8 & T. interdigitale & 5.0 \\
\hline 9 & C. freundii & - & & & \\
\hline 10 & S. typhi 14028 & - & & & \\
\hline 12 & S. saprophyticus A & - & & & \\
\hline 13 & S. saprophyticus B & - & & & \\
\hline 14 & S. epidermidis A & - & & & \\
\hline 15 & S. epidermidis B & - & & & \\
\hline 16 & S. epidermidis C & - & & & \\
\hline 17 & S. typhi 14028 & - & & & \\
\hline 18 & B. cereus & - & & & \\
\hline
\end{tabular}




\section{References}

1. Prakasham RS, Kumar BS, Kumar YS, Kumar KP. Production and characterization of protein encapsulated silver nanoparticles by marine isolate Streptomyces parvulus SSNP11. Indian J Microbiol. 2014;54(3):329-336.

2. Sun YG, Mayers B, Herricks T, Xia YN. Polyol synthesis of uniform silver nanowires: A plausible growth mechanism and the supporting evidence. Nano Lett. 2003;3(7):955-960.

3. Duran N, Marcato PD, Alves OL, Souza G, Esposito E. Mechanistic aspects of biosynthesis of silver nanoparticles by several Fusarium oxysporum strains. J Nanobiotechnology. 2005;3:1-7.

4. Meruvu H, Vangalapati M, Chippada SC, Bammid SR. Synthesis and characterization of zinc oxide nanoparticles and its antimicrobial activity against Bacillus subtilis and Escherichia coli. Rasayan J Chem. 2011;4(1):217-222.

5. Yedurkar S, Maurya C, Mahanwar P. Biosynthesis of zinc oxide nanoparticles using Ixora coccinea leaf extract: A green approach. Open J Synth Theor Appl. 2016;5(1):1-14.

6. Agarwal H, Venkat Kumar S, Rajeshkum S. A review on green synthesis of zinc oxide nanoparticles: An eco-friendly approach. Resource-Efficient Technologies. 2017;3(4):406-441.

7. Kolekar TV, Bandgar SS, Shirguppikar SS, Ganachari VS. Synthesis and characterization of $\mathrm{ZnO}$ nanoparticles for efficient gas sensors. Arch Appl Sci Res. 2013;5(6):20-28.

8. Applerot WE, Holleman AF. Inorganic Chemistry. Elsevier 22: 24-34 Brayner, Basu, 2006. Elsevier 2009; 1225-1229.

9. Lakshmi JV, Sharath R, Chandraprabha MN, Neelufar E, Abhishikta H, Malyasree P. Synthesis, characterization and evaluation of antimicrobial activity of zinc oxide nanoparticles. J Biochem Technol. 2012;3(5):S151-S154.

10. Gunalan S, Sivaraj R, Rajendran V. Green synthesized ZnO nanoparticles against bacterial and fungal pathogens. Prog Nat Sci Mat Inter. 2012;22(6):693-700.

11. Mahanty A, Mishra S, Bosu R, Maurya UK, Netam SP, Sarkar B. Phytoextracts-synthesized silver nanoparticles inhibit bacterial fish pathogen Aeromonas hydrophila. Indian J Microbiol. 2013;53(4):438446. http://dx.doi.org/10.1007/s12088-013-0409-9

12. Ramesh $P$, Rajendran A, Meenakshisundaram M. Green synthesis of zinc oxide nanoparticles using flower extract Cassia auriculata. Journal of NanoScience and NanoTechnology. 2014;2(1):41-45.

13. Burkill HM. The Useful Plants of West Africa, Familie E-I and J-L, 2 and 3. $2^{\text {nd }}$ ed. Kew, UK: Royal Botanic Gardens; 1995:151-153.

14. Doughari JH, Okafor B. Antimicrobial activity of Senna alata Linn East Central African J Pharmaceut Sci. 2007;1(10):17-21.

15. Ogunti EO, Elujoba AA. Laxative activity of Cassia alata oil leaf. Fitoterapia. 1993;64:437-439.

16. Ogunjobi AA, Abiala MA. Antimicrobial activity of Senna alata and Phyllanthus amarus. Global J Pharmacol. 2013;7(2):198-202.

17. Salam AH, Sivaraj R, Venckatesh R. Green synthesis and characterization of zinc oxide nanoparticles from Ocimum basilicum L. var. purpurascens Benth.-Lamiaceae leaf extract. Mater Lett. 2014;131:1618. http://dx.doi.org/10.1016/j.matlet.2014.05.033

18. Samat NA, Nor RM. Sol-gel synthesis of zinc oxide nanoparticles using Citrus aurantifolia extracts. Ceram Int. 2013;39:S545-S548.

19. Vijayakumar S, Vinoj G, Malaikozhundan B, Shanthi S, Vaseeharan B. Plectranthus amboinicus leaf extract mediated synthesis of zinc oxide nanoparticles and its control of methicillin resistant Staphylococcus aureus biofilm and blood sucking mosquito larva. Spectrochim Acta Part A Mol Biomol Spectrosc. 2015;137:886-891.

20. Jha AK, Kumar V, Prasad K. Biosynthesis of metal and oxide nanoparticles using orange juice. J Bionanosci. 2011;5(2):162-166. http://dx.doi.org/10.1166/jbns.2011.1053

21. Rajiv P, Rajeshwari S, Venckatesh R. Rambutan peels promoted biomimetic synthesis of bioinspired zinc oxide nanochains for biomedical applications. Spectrochim Acta Part A Mol Biomol Spectrosc. 2013;112:384-387.

22. Divyapriya S, Sowmia C, Sasikala S. Synthesis of zinc oxide nanoparticles and antimicrobial activity of Murraya koenigii. World J Pharm Pharm Sci. 2014;3(12):1635-1645.

23. Balouiri M, Sadiki M, Ibnsouda SK. Methods for in vitro evaluating antimicrobial activity: A review. J Pharm Anal. 2016;6(2):71-79.

24. Ambika, S, Sundrarajan M. Antibacterial behaviour of Vitex negundo extract assisted $\mathrm{ZnO}$ nanoparticles against pathogenic bacteria. J Photochem Photobiol B. 2015;146:52-57.

25. Suresh D, Nethravathi PC, Gowda UCH, Raja NNH, Bhushana N, Sharma SC. Green synthesis of multifunctional zinc oxide ( $\mathrm{ZnO})$ nanoparticles using Cassia fistula plant extract and their photodegradative, antioxidant and antibacterial activities. Mat Sci Semiconductor Proc. 2015;31:446-454.

26. Jamdagni $P$, Khatri $P$, Rana JS. Green synthesis of zinc oxide nanoparticle using flower extract of Nyctanthes arbor-tristis and their antifungal activity. J King Saud Uni Sci. 2018;30(2):168-175.

27. Ramesh M, Anbuvannan M, Viruthagiri G. Green synthesis of $\mathrm{ZnO}$ nanoparticles using Solanum nigrum leaf extract and their antibacterial activity. Spectrochim Acta Part A Mol Biomol Spectrosc. 2015;136 (Pt B):864-870.

28. Singh C, Sharma V, Naik PK, Khandelwal V, Singh H. A green biogenic approach for synthesis of gold and silver nanoparticles using Zingiber officinale. Dig J Nanomat Bios. 2010;6(2):535-542.

29. Chitsazi MR, Korbekandi H, Asghari G, Najafi RB, Badii A, Iravani S. Synthesis of silver nanoparticles using methanol and dichloromethane extracts of Pulicaria gnaphalodes (Vent.) Boiss. aerial parts. Artif Cells Nanomed Biotechnol. 2016;44(1):328-333.

30. Raliya R, Tarafdar JC. Biosynthesis and characterization of zinc, magnesium and titanium nanoparticles: An eco-friendly approach. Interl Nano Let. 2014;4:93.

31. He L, Rodda T, Haynes C, et al. Detection of a foreign protein in milk using surface-enhanced Raman spectroscopy coupled with antibody-modified silver dendrites. Anal Chem. 2011;83(5):1510-1513.

32. Dubey SP, Lahtinen M, Sillianpaa M. Tansy fruit mediated greener synthesis of silver and gold nanoparticles. Process Biochem. 2010;45(7):1065-1071.

33. Oboh PA, Abulu EO. The antimicrobial activities of extracts of Psidium guajava and Citrus aurantifolia. Nig J Biotechnol. 1997;8:25-27.

34. Dias MA, Lacerda ICA, Pimentel PF, de Castro HF, Rosa CA. Removal of heavy metals by an Aspergillus terreus strain immobilized in a polyurethane matrix. Let Appl Microbiol. 2002;34(1):46-50.

35. Iravani S, Zolfaghari B. Green synthesis of silver nanoparticles using Pinus eldarica bark extract. Biomed Res Inter. 2013;2013:639725.

36. Suliman RS, Ali H, Nurulain I, et al. Cinnamon bark extract for the formulation and characterisation of antimicrobial cream. Inter J Res Ayurveda Pharm. 2017;8(2):200-206. 